nized at the Ghent conference that this might appear to be different in different countries. Very roughly speaking, Northern Europe seemed to be lagging behind the South, perhaps owing to cultural differences. It was felt that ensuring a good example was set should be an important issue, and in this regard countries such as Italy, Spain and France had an advantage over, for instance, the Scandinavian countries. There are, relatively speaking, more women working in physics in the former countries than in the latter, whereas in the latter it is unusual to find a female physics professor in, for instance, a university.

\section{Forum on Education}

The Forum on Education recently set up a Board to discuss ways to proceed with activities on the European scale. An immediate task is to help organize a session on physics education at the next EPS General Conference Trends in Physics (Seville; September 1996). The Forum must also contact other organizations with similar goals such as, for instance, the IUPAP International Commission on Physics Education, the American Physical Society's Forum on Education and GIREP, the International Research Group on Physics Teaching. It was also proposed at Ghent to call on the Forum on Education to help establish the European Physics Education Network (EUPEN). The main lines of action of this network have been formulated and an application for financial support is to be sent to the European Community under the Socrates framework. It is noted that EUPEN plans to have a broader range of activities than the Forum on Education, for it would also assume responsibility for issues on university teaching as well as student and teacher exchange programmes.

For countries with physical societies or equivalent organizations such as The Institute of Physics in the United Kingdom which are already very active in promoting interest in physics at all levels (schools, universities, the general public, etc.), an EPS effort may seem superfluous. However, it is my belief that information about activities within these countries could serve as examples for others, and thus help increase efforts to pursue the important task of promoting an interest in physics among young people throughout Europe.

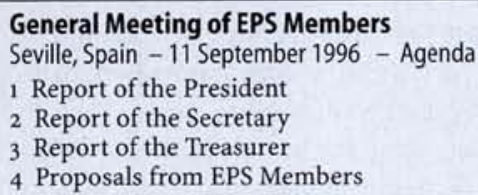

\title{
Mulhouse and Beyond
}

\section{The EPS Executive Committee and the EPS Council made the following decisions at meetings in Lisbon on 21-23 March 1996.}

\section{Executive Committee}

- Strategy Plan - To seek Council approval for a Strategy Plan for EPS which in addition to routine tasks, emphasises issues of professional physics, care for the next generation of physicists, east-west cooperation, and public awareness and information dissemination.

- Implementation - To recommend to Council that proposals for activities encompassed by the Strategy Plan be submitted to the Secretary General by 1 October 1996 so that they can be considered for the plan's implementation.

- To recommend to Council that activities be contracted out to national societies and other bodies wherever possible in order to limit the amount of EPS administration.

- Unit Fee - To seek Council approval for changing the unit fee from Swiss francs to the ECU based upon the average rate of exchange for the period 1 January - 1 April 1996. This stems from the Executive Committee's decision (announced to members in December 1995) to move the Secretariat to Mulhouse with the Budapest office remaining for at least two more years.

- Europhysics Letters - In agreement with the Management Board of Europhysics Letters $(E P L)$, to separate the EPS and EPL managements so that some EPS staff members no longer work for both EPS and EPL. This decision should have no effect on the journal's scientific direction whereby EPS nominates the Editorial Board and the Editor-in-Chief.

- Secretary General - To create a task force charged with identifying a candidate for Secretary General who would start working on 1 January 1997 with the object of taking office when the present Secretary General retires. - To seek proposal for candidates from National Member Societies.

- Finances - To propose that Council accept the audited accounts for 1995 seeing a net profit for the year of $62.5 \mathrm{kSFR}$, after the attribution of 59 kSFR to the Special Development Fund, that would eliminate the Society's accumulated deficit.

- To propose to Council a budget for 1996 that envisages a surplus of $29.8 \mathrm{kSFR}$.

- To present a budget for 1997 that would be broken down according to activities.

- Funds - To approve the Conference Committee's recommended criteria for Solidarity Fund grants to conference participants.

- That decisions on requests for allocation of monies from special funds be jointly decided by the Treasurer, the Secretary General and the chairman of the appropriate EPS body.

- Committees - To appoint J. Nadrachal as the Chairman of a task force that would coordinate east-west initiatives at the national level. - To appoint J. Charap as the Chairman of the Physics and Society Action Committee.

- Following the call for nominations to expand the Editorial Board of Europhysics News, to appoint D. Haarer, the German Physical Society's nominee.

- To appoint the Internet Coordination
Group's nominees for National WWW Coordinators put forward by national societies.

- Honourary Members - To accept a proposal by the task force charged with nominating new Honourary Members, who must by living persons, that a replacement for A.R. Mackintosh (who died in December 1995) should, as a mark of honour, not be put forward.

- European Union - To delegate D.L. Weaire, the proposed President-Elect, to promote the Society's contacts with the European Union.

- EPS Prizes - That the Executive Committee consults with Divisions and Groups before creating special prizes.

- To harmonise, with Divisions and Groups, the rules for EPS prizes, including a possible rule requiring that awards be ratified by the Executive Committee.

- Register Commission - To accept the nomination of 10 new applicants for admission to the Register of European Physicists (Eur Phys). In the case of applicants from less-favoured regions who have difficulty paying the fees, to ask the Chairman of the Register Commission to seek EPS support on an individual basis.

- To pay, for one year, for the distribution of Europhysics News to members joining the Register who do not receive the bulletin.

- European Mobility Scheme for Physics Students - To accept 4 new participating institutions, bringing the total number to 178 .

- Conferences - To extend the deadlines for registration and abstracts for the EPS-10 General Conference and to seek clarification of payment arrangements and hotel prices. - To seek proposals from national societies for hosting the next international conference on Research and Communications in Physics $(R A C I P-3)$ in Europe in the year 2000.

\section{Council}

- Constitution \& By-laws - To accept the changes announced to members that the EPS be incorporated in Alsace/Moselle, France, with its seat in Mulhouse.

- Unit Fee - To change the currency of the unit fee from Swiss francs to the ECU.

- To reduce the unit fee from the Executive Committee's proposed average rate of about 9.7 ECU to 9.1 ECU.

- That the Executive Committee considers proposing a unit fee increase within 2 years.

- Strategy Plan - To accept the Strategy Plan. - To encourage National Member Societies to incorporate the plan in their own plans.

- To include in the plan's implementation proposals put forward by EPS bodies and a budget based on activities.

- Finances - To approve the 1995 accounts, the 1996 budget and the proposal that the 1997 budget be broken down according to activities.

- Members - To appoint S.R. Edwards, E. Heer and $\mathrm{H}$. der Waard as Honourary Members.

- To accept 123 new Individual Ordinary Members (IOMs), bringing the total number of IOMs to 3579 ( 3927 at the end of 1994). 
- European Mobility Scheme for Physics Students - That the Executive Committee consider a Polish Physical Society proposal that it take over the mobility scheme secretariat. - That students participating in the scheme be offered one-year's membership free-of-charge.

- Professional Qualifications - To approve the Register Commission's proposal that the Executive Committee considers providing financial support from EPS to cover the fees of applicants from less-favoured regions.

- That the Commission considers changing the currency of the registration fee to the ECU.

- Internet Coordination Group - That the ICG makes proposals to the Executive Committee on the possibility of having Division and Group membership lists available on Internet.
- Divisions - To have a final agreement for the an EPS-European Astronomy Society Joint Division of Physics and Astronomy ready for approval by the Societies' Councils in 1997.

- Next Meeting - To hold the next Council meeting in Mulhouse on the announced dates (21-22 March 1997). The 1998 meeting would then be in Holland (on 27-28 March).

- Executive Committee - To elect the following: President: H. Schopper, Geneva; PresidentElect: D.L. Weaire, Dublin; Secretary: J.-P. Ansermet, Lausanne; Vice-Secretary: C.

Sébenne, Paris; Treasurer: J.L. Lewis, Malvern; Vice-Secretary: E. Osnes, Oslo; Members: S.

Bagayev, Novosibirsk; G. Benedek, Milan; C.M. Ferreira, Lisbon; G.C. Morrison, Birmingham; M.J. van der Wiel, Nieuwegian.

\section{Many Opportunities for Collaboration}

The EPS Internet Coordination Group (ICG) and the EPS Publications Committee ad hoc Discussion Group for Online Publications organized a discussion meeting in Paris on 26 February to review developments in electronic communication in science, current activities carried out under the EPS EurophysNet umbrella, and plans for future action. The meeting was divided into sessions on indexing, electronic publications and information services to reflect EPS initiatives involving Oldenburg University's PhysNet index services, the EurophysNet information service supervised by the ICG and the deliberations of the Publications Committee, part of which involve a Task Force on Electronic Publishing. In a short introduction, Franck Laloë (ENS Paris) who chairs the Publications Committee, spoke of the pressure from colleagues to exploit electronic means of communication and to consolidate the proliferating sources of information. He felt that the EPS was in a good position to act, at least as a coordinator. WWW URLs of the services described below are available in europhysicsnews extra (March-April 1996) on EurophysNet at http://epswww.epfl.ch.

\section{PhysDep Expansion}

The first pilot project to be operated under the EurophysNet umbrella, namely the PhysDep indexing service, was reviewed by Eb Hilf (Oldenburg University). PhysDep allows one to search for information (research topics, fax numbers, teaching materials, etc.) found on the WWW pages of European Physics Institution Servers. The service is in the process of being upgraded by ensuring that the indexed pages are authorised by institutions and by encouraging the use of tags and keywords to improve the indexing. It was felt at the meeting that the authorization procedure needed top-down action as well as the bottom-up identification of sources using search engines. The ICG has therefore recently asked national physical societies to nominate National WWW Coordinators who would help ensure that physics institutions name authorised WWW server sites which they then make known to PhysDep.

Eb Hilf envisaged a series of index services for various topics, each operating under the PhysNet banner and collaborating with groups specialising in particular topics. Like PhysDep, they could be super-

Oldenburg's PhysNet team in action. From the left, Heinrich Stamerjohanns, Eb Hilf and Thomas Severiens. PhysNet operates, under the EPS World-Wide Web EurophysNet umbrella, a series of indexes (PhysDep, PhysDoc, PhysDis) based on the Harvest search engine. vised by EPS under the EurophysNet umbrella, and perhaps carry the EPS logo as long as they fulfil set standards.

\section{TIPTOP Collaboration}

A group based at the Technical University of Vienna maintains a list of physics servers as part of a well-known collection of useful physics links called Physics Around the World (PAW). The site's developers (Mikko Karttunen, a student at McGill University in Canada, and Günther Nowotny from the TU Vienna) agreed at the meeting that PAW would collaborate with PhysDep to create a single list PhysNet of physics institution servers. It will be mirrored at The Internet Pilot TO Physics (TIPTOP) to which $P A W$ now belongs.

TIPTOP is a new "world-wide, onestop, knowledge-server", and Mikko Karttunen described how it took shape in the early 1990 s when he and Nowotny created PAW. The TIPTOP team has automated the laborious work of running a state-of-theart global information service over WWW

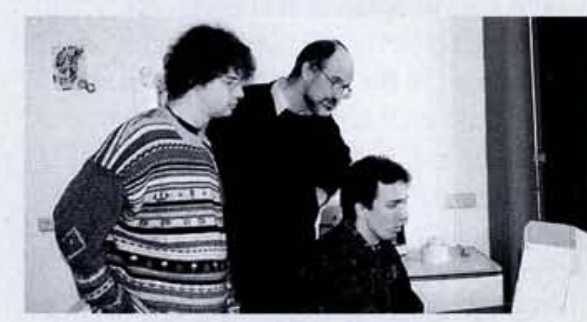

using a dedicated server in Sweden. The MIT-based Net Advance of Physics has joined the project, bringing a subject index to archival literature as well as a US site.

TIPTOP operates sophisticated upload facilities that allow users to input information that can then be made available in a systematic fashion over the WWW. It was agreed at the meeting that the complementary PhysDep and TIPTOP upload facilities will be coordinated to ensure that physics institutions have a highly visible entry point for updating the institution list.

\section{PhysDoc and PhysDis}

PhysNet launched late last year a second service, called PhysDoc, which indexes documents stored on PhysDep servers. Thomas Severiens, a student from Oldenburg University who helped establish PhysDep, outlined the reasons for selecting the Harvest search machine (it is one of the best available and lies in the public domain). In the case of PhysDoc, indexed information may be either full texts or bibliographic information, depending on how an author stores a document locally. PhysDoc complements the centralized e-print bulletin board system based at the Los Alamos National Laboratory (LANL), especially for fields where no e-print slots exist and for non-permanent documents, large graphic-oriented papers, annual reports, and scanned-in texts.

In order to enlarge PhysDoc's coverage beyond the present 3000 documents stored in servers based at 70 European institutions, the ICG is in the process of contacting physics institutions through the national coordinators to ask them to make sure that the document archives are known to PhysDoc. PhysNet is also planning to enlarge the scope by establishing an index (PhysDis) for $\mathrm{PhD}$ theses. In this case, authenticity is extremely important and has to be guaranteed by institutions. It is envisaged that the national coordinator scheme will lead to the necessary authenticity, and that PhysDis will also operate under the PhysNet banner as a EurophysNet service supervised by the ICG.

It is also necessary to improve PhysDoc and PhysDis indexing by ensuring that the search engines identify relevant documents. Information providers can help by using a short list of metatags or keywords. Paul Ginsparg (LANL) suggested that indexing information contained in the headers of PostScript files can also be accessed. It was therefore agreed that physics institutions would be asked by the ICG through national coordinators to incorpo- 